Original Article

\title{
The Outcome of Subaxial Cervical Injury in Adult Patients Managed Surgically Through an Anterior Approach
}

\author{
Aurangzeb Kalhoro ${ }^{1}$, Abdul Samad Panezai ${ }^{2}$, Sher Hassan², Farrukh Javeed ${ }^{3}$, Lal Rehman ${ }^{3}$ \\ ${ }^{1}$ Jinnah Medical and Dental College, Karachi, Pakistan, ${ }^{2}$ Sandeman civil hospital, Quetta, Pakistan \\ ${ }^{3}$ Jinnah Postgraduate Medical Centre, Karachi, Pakistan.
}

\begin{abstract}
Objectives: We determined the Outcome of subaxial cervical injury management in adults through anterior approach open reduction and fixation injury $<72$ hours.

Material and Methods: A total of 71 patients declared to have a recent chronicle of traumatic cervical spine injury with a conventional diagnosis of subaxial injury by Magnetic Resonance Imaging (MRI) and XRay anteroposterior and lateral views. ASIA Impairment Scale was used for assessment and was done at the time of admission and after six months.

Results: Mean age of the patients in our study was $38.54 \pm 5.47$ years. According to American Spinal Injury Association (ASIA) scale, improvement by two grades was seen in 18 cases and improvement by one - grade was observed in 48 cases. Mortality was seen in 5 cases, where 2 deaths were related to associated injury, one related to a complication of surgery and other 2 died due to aspiration complications. Out of 66 cases, the outcome was good in 49 (74.29\%) and fair in 17 (25.76\%).
\end{abstract}

Conclusion: The study results revealed that Anterior Cervical Discectomy and Fusion (ACDF) is considered to be a better treatment choice for better anatomical stabilization of the spine with early reduction.

Keywords: Subaxial cervical injury, anterior approach, ASIA (American Spinal Injury Association) scoring.

\section{Corresponding Author:}

Aurangzeb Kalhoro

Jinnah Medical Dental College, Karachi

Email: draurangzebkalhoro@gmail.com

Date of Submission: 02-10-2020

Date of Revision: 27-10-2020

Date of Online Publishing: 25-12-2020

Date of Print: 30-12-2020

DOI: $10.36552 /$ pjns.v24i4.491

\section{INTRODUCTION}

The subaxial cervical spine injury is considered as one of the major causes of death and morbidity in the general population. ${ }^{1}$ The incidence annually is around 12 to 58 cases per million, and injury to the cervical spine is seen in $2 \%$ to $3 \% .^{2}$ Road traffic accidents and falling from height are considered as the common mechanisms of cervical injuries which with associated trauma to other parts of the body. ${ }^{3}$ Multiple surgical operations are available for the cervical spine 
injury, either it is managed in one stage anterior, posterior or combined with both the approaches. $^{4-5}$ The strategies are modified based on the condition of subaxial cervical spine injury. CT scan of the cervical spine is considered as one of the most highly sensitive investigations, but $\mathrm{MRI}$ cervical spine relates the issue with the cord contusion disc, protrusion and is considered very informative respectively. ${ }^{6}$ Cervical injury patients with multiple organ injuries pose challenges for care providers starting from trauma sites and then transfer to definitive care management ${ }^{7}$. Polytrauma patients must be given protocol treatment until radiological exclusion is carried out, issues like hypoxemia and hypotension can add to the severity of cord injury which should be promptly treated. ${ }^{8}$ Complications related secondary to cervical spine injuries such as pressure ulcers, chest congestion, thromboembolic disease, urinary issues, and the gut issue must be managed under multidisciplinary management to reduce morbidity 9 . The spinal surgeon has given quality work, but an injury at different cervical spine is continued to explore different horizon. ${ }^{10}$ The current study aimed to identify the frequency and etiological causes of cervical spine injury and calculation based on American Spinal Injury Association (ASIA) classification, for the patients who present at a tertiary care hospital in Pakistan, the developing country.

\section{MATERIAL AND METHODS}

\section{Study Design \& Setting}

The cross-sectional prospective study for three years from $16 / 07 / 2016$ to $20 / 08 / 2019$ at the Neurosugery ward of J.P.M.C, (Jinnah Postgraduate Medical Centre), Karachi.

\section{Inclusion Criteria}

Patients included who reported about 17 years of age history related to cervical trauma as early as seventy-two hours.

\section{Exclusion Criteria}

The patients below the age of 17 years, preexisted bone-lesions like a tumor or any infection and congenital anomaly were excluded.

\section{Data Collection}

After ethical approval from the hospital committee and the informed consents from patients $(n=71)$ with the traumatic injury with a conventional diagnosis of subaxial injury by Magnetic Resonance Imaging (MRI) and X-Ray anteroposterior view and lateral view of the cervical spine. Impairment measured on ASIA (American Spinal Injury Association) Scale was used for assessment was done on admission date and after six months follow-up. The patient was kept in a high dependency unit, a neurological exam was documented pre-surgery and at followup after 6 months. Antibiotic was given, physiotherapy was advised postoperatively.

\section{Data Analysis}

The data was analyzed for mean \pm standard deviation for quantitative data and frequencies were calculated for qualitative data in the statistical program SPSS version 23.

\section{Surgical Procedure}

Patients were operated under general anesthesia in supine position with cervical traction. Surface marking was done at the cervical spine for the incision under aseptic measures and then the incision was made. A medial border of sternocleidomastoid was followed up to the cervical spine. The traumatic cervical level was confirmed with $\mathrm{C}$ arm. An involved disc was removed. The corpectomy was done, the graft was taken from the anterior superior iliac spine. 
The graft was shaped according to corpectomy space. The graft was placed in situ. The traction was removed and the cervical plate was applied. The hemostasis was done. The drain was done and the wound was closed layer by layer. The collar was applied. Antibiotics ceftriaxone and gentamicin were given.

\section{RESULTS}

Seventy-one cases with chronicle history within the time frame of less than 72 hours were included in the study.

\section{Age Incidence}

The median age was approximate $38.54 \pm 5.47$ years, with maximum age was 60 years and minimum age was 18 years. There were 11 patients with age less than 30 years, 29 patients in the age group 31 - 40 years, 22 patients in $41-$ 50 years and 9 patients in $51-60$ years.

\section{Gender Distribution}

Among seventy-one cases, 48 (68\%) were male and 23 (32\%) were female.

\section{Clinical Presentation}

Accordingly, most of the trauma was related to traffic accidents observed in $53.3 \%$ of the cases, followed by falling from and cases afflicted with assault $22.5 \%$ height $23.9 \%$.

\section{Cervical Injury Level}

Patient cervical injury level is presented in Table 1, corresponded with C5 - 6 levels of injury, which was observed in $43.7 \%$, the Cervical $6-7$ level was $23.95 \%$, while injury to C4 - 5 was observed in $19.7 \%$ and at Cervical 3-4 it was $12.7 \%$ cases.

\section{ASIA Grade Improvement}

Post-surgical improvement in the patient was

based on ASIA grading system Grade "Two" (ASIA) scale improvement was seen in 18 (25.3\%) cases, while one-grade improvement was seen in 48 (67.6\%) surgeries (Table 2).

\section{Graft Placement}

Fusion was done with bicortical bone graft, the graft was taken from the right anterior superior iliac spine in all the patient right.

\section{Complications}

During the study, five $(7.04 \%)$ patients were expired, one expiry was due to the surgical complication, two patients had aspirated, two expired due to multiple associated injuries.

Table 1: Level of Trauma.

Level of trauma

Cervical 5-Cervical 6

Cervical 6-Cervical 7

Cervical 4-Cervical 5

Cervical 3-Cervical 4

\begin{tabular}{rc} 
n & $\%$ \\
31 & $43 \%$ \\
17 & $24 \%$ \\
14 & $20 \%$ \\
9 & $13 \%$ \\
\hline
\end{tabular}

Table 2: Asia Score With At 6 Months.

\begin{tabular}{|lccc|} 
& $\mathbf{n}$ & $\begin{array}{c}\text { Initial ASIA } \\
\text { Scale }\end{array}$ & $\begin{array}{c}\text { After 6-Month } \\
\text { ASIA Scale }\end{array}$ \\
Improved two & 08 & $C$ & $E$ \\
grades & 04 & $B$ & $D$ \\
Improved one & 06 & $A$ & $C$ \\
Grade & 27 & $B$ & $C$ \\
\hline
\end{tabular}

Table 3: Outcome Related With Age Groups.

\begin{tabular}{lccl} 
Age Groups & $\mathbf{n}$ & Good & \multicolumn{1}{c}{ Fair } \\
$\leq 30$ & 11 & $6(54 \%)$ & $5(45 \%)$ \\
31 to 40 & 28 & $23(82 \%)$ & $5(17 \%)$ \\
41 to 50 & 19 & $16(84 \%)$ & $3(15 \%)$ \\
51 to 60 & 8 & $5(62.5 \%)$ & $3(37.5 \%)$ \\
\hline
\end{tabular}

\section{Outcome}

Out of 66 cases, 49 (74.29\%) were considered a 
good outcome and around 17 (25.76\%) were poor outcomes after six months follow-up. Table 3 shows the outcome related to age groups.

\section{DISCUSSION}

We identified the frequency and etiological causes of cervical spine injury and calculation based on American Spinal Injury Association (ASIA) classification. A timely revival of such study will help to improve the management of the patient, help us to improve traumatic management of cervical spine and may help to decrease morbidity and mortality.A study conducted by Quarrington et al. ${ }^{11}$ included cervical spine injury patients and found that $51.2 \%$ injuries were related to unilateral dislocation, while $48.8 \%$ had bilateral facet dislocation. The same study also quoted that about $38.5 \%$ of their patients were young with most common involvement of C6/C7 spinal level. Our study also showed young adults more commonly involved in cervical spine injuries. The most common level involved in our study was C5/C6 while second commonest was C6/C7. CT spine and MRI cervical spine both were accurate and preferable modalities used for cervical spinal cord injury, as stated by Izzo et al. ${ }^{12}$ Similarly, we also used both these modalities as standard in our study to assess the cervical spinal injury grade it.In another study, 23 patients treated conservatively in the initial phase had a follow-up of around 171 days, all showed at least some improvement. Surgically treated patients in their groups were 15 with 140 days of follow-up. According to the surgical group, 11 patients (73.3\%) were associated with ASIA A, 2 to AIS B (13.3\%) and 2 to ASIA C (13.3\%). ${ }^{13}$ While at our centre, the observation of two grade improvement was reported in about eighteen cases, while grade one American Spinal Cord Injury Association (ASIA) Scale Improvement was found in about 48 cases. Zaveri et al $^{14}$ considered intravenous use of methylprednisolone in early spinal cord injuries in their study group but this treatment is still controversial. Non-operative treatment in their studied population consisted of external mobilization for a period of 8 to 12 weeks and found that the goals of surgery were to decompress the cord, maintain alignment of the vertebral column, and stabilize the spine. Comparatively, we also recommended a nonmobilization for 2 months and prolonged physiotherapy for the patients.

A study by Fredø et al $^{15}$ stated the median age of the patients to be 48 years and approximately $74 \%$ consisted of males and $43 \%$ had spinal cord injuries and isolated radiculopathy observed in $27 \%$. The average duration between injuries to surgery in their study was 2 days. Mortality of $2.3 \%$ was observed in operated cases (death within 30 days of operation). The need for re-operation was seen in $7.3 \%$ cases. A follow-up of 2.6 years was conducted after the trauma in cervical spine injury patients who had survived. Patients showed improvement in ASIA grade by atleast one or two in about $51 \%$ cases. About $89 \%$ of the patients with preoperative radiculopathy improved and were without symptoms on follow-ups. Han et al ${ }^{16}$ considered the follow-up 27.6 months, where one Frankel grade improvement was observed in 21 cases (21.4\%). This study showed complete fusion in all of their patients. Anissipour et $\mathrm{al}^{17}$ in their study shared the data of thirty-six patients having facet dislocations treated with Anterior Cervical Discectomy and Fusion (ACDF) with a locking fixed plate and followed them for 323 days. Unilateral facet injury was seen in 16 of their patients while twenty patients had bilateral facet injuries. Failure in treatment with ACDF was observed in 3 patients out of 36 (8\%). All of these failures were seen within 4 weeks duration, one had a facet fracture while others were with endplate fracture.

A study by Lozano et al $^{18}$ showed no case of cervical fusion infection (wound) in patients treated with early tracheostomy, but 5 patients 
$(8.47 \%)$ showed infections in patients with delayed tracheostomy. In their study wound infection was seen in four patients treated with fusion surgery through a posterior approach while one showed infection in anterior approach. No difference was observed in both groups in terms of duration of hospital stay and mortality. In our study, only 8 patients underwent tracheostomy but no case of infection was observed, although all cases were operated with anterior fusion under aseptic method with antibiotic cover to minimize the infection.

\section{CONCLUSION}

The study results showed that: ACDF is considered to be a better treatment for the restoring normal anatomical configuration along with the stabilization of the spine with early reduction. Early decompression of cord, early mobilization helps in a minimum hospital stay and the overall management cost is reduced with a better outcome for the developing countries.

\section{LIMITATIONS}

This was a single centre study. We had a short follow-up, and the effect of associated mild injuries to other organ was not included was not included.

\section{REFERENCES}

1. Casper DS, McKenzie J, Schroeder GD. Controversial cervical spine fractures: Classification and treatment. In Seminars in Spine Surgery, 2017; 29 (1): 41-49. WB Saunders.

2. Dhakal GR, Bhandari $R$, Dhungana $S$, Poudel $S$, Gurung G, Kawaguchi $Y$, Riew KD. Review of Subaxial Cervical Spine Injuries Presenting to a Tertiary-Level Hospital in Nepal: Challenges in Surgical Management in a Third World Scenario. Global Spine Journal, 2019; 9 (7): 713-6.

3. Al-Samouly HM, Taha AM. Comparative Study of Surgical Approaches for Distractive Flexion Injuries of Sub-Axial Cervical Spine. Open Journal of Modern Neurosurgery, 2018; 8 (3): 342-51.

4. Jiang $X$, Yao $Y, Y u$, Cao $Y$, Yang $H$. Surgical treatment for subaxial cervical facet dislocations with incomplete or without neurological deficit: a prospective study of 52 cases. Medical science monitor: international medical journal of experimental and clinical research, 2017; 23: 732.

5. Ding C, Wu TK, Gong Q, Li T, Ma LT, Wang BY, Deng $Y X$, Liu $\mathrm{H}$. Anterior release and nonstructural bone grafting and posterior fixation for old lower cervical dislocations with locked facets. Medicine (Baltimore), 2017 Nov; 96 (46): e8809.

Doi: 10.1097/MD.0000000000008809.

6. Mascarenhas D, Dreizin D, Bodanapally UK, Stein DM. Parsing the utility of CT and MRI in the subaxial cervical spine injury classification (SLIC) system: is CT SLIC enough? American Journal of Roentgenology, 2016; 206 (6): 1292-7.

7. Yue JK, Winkler EA, Rick JW, Deng $H$, Partow CP, Upadhyayula PS, Birk HS, Chan AK, Dhall SS. Update on critical care for acute spinal cord injury in the setting of polytrauma. Neurosurgical Focus, 2017; 43 (5): E19.

8. Joaquim $A F$, Rodrigues $S A, D A$ Silva $F S$, DA Silva OT, Ghizoni E, Tedeschi H, Schroeder GD, Vaccaro AR, Patel AA. Is There an Association With SpinoPelvic Relationships and Clinical Outcome of Type A Thoracic and Lumbar Fractures Treated NonSurgically? Int J Spine Surg. 2018 Aug. 15; 12 (3): 371-376. Doi: 10.14444/5043.

9. Fariña $M M$, de la Barrera SS, Marqués AM, Velasco MF, Vázquez RG. Update on traumatic acute spinal cord injury. Part 2. Medicina Intensiva (English Edition). 2017; 41 (5): 306-15.

10. Du JP, Fan Y, Zhang JN, Liu JJ, Meng YB, Hao DJ. Early versus delayed decompression for traumatic cervical spinal cord injury: application of the AO Spine subaxial cervical spinal injury classification system to guide surgical timing. European Spine Journal, 2019; 28 (8): 1855-63.

11. Quarrington RD, Jones $C F$, Tcherveniakov $P$, Clark JM, Sandler SJ, Lee YC, Torabiardakani S, Costi JJ, Freeman BJ. Traumatic subaxial cervical facet subluxation and dislocation: epidemiology, radiographic analyses, and risk factors for spinal 
cord injury. The Spine Journal, 2018; 18 (3): 387-98.

12. Izzo R, Popolizio T, Balzano RF, Pennelli AM, Simeone $A$, Muto $M$. Imaging of cervical spine traumas. Eur J Radiol. 2019; 117: 75-88.

Doi: 10.1016/j.ejrad.2019.05.007.

13. Joaquim AF, Ghizoni E, Tedeschi $H$, Yacoub AR, Brodke DS, Vaccaro AR, Patel AA. Upper cervical injuries: clinical results using a new treatment algorithm. Journal of Craniovertebral Junction \& Spine, 2015; 6 (1): 16.

14. Zaveri G, Das G. Management of sub-axial cervical spine injuries. Indian Journal of Orthopedics, 2017; 51 (6): 633.

15. Fredø HL, Rizvi SA, Rezai $M$, Rønning $P$, Lied $B$, Helseth E. Complications and long-term outcomes after open surgery for traumatic subaxial cervical spine fractures: a consecutive series of 303 patients. BMC Surgery, 2016; 16 (1): 56.

16. Han MS, Lee GJ, Kim JH, Lee SK, Moon BJ, Lee JK. Outcomes of Anterior Cervical Fusion Using
Polyetheretherketone Cage with Demineralized Bone Matrix and Plate for Management of Subaxial Cervical Spine Injuries. Korean Journal of Neurotrauma, 2018; 14 (2): 123-8.

17. Anissipour AK, Agel J, Baron M, Magnusson E, Bellabarba C, Bransford RJ. Traumatic cervical unilateral and bilateral facet dislocations treated with anterior cervical discectomy and fusion has a low failure rate. Global Spine Journal. 2017; 7 (2): 110-5.

18. Lozano CP, Chen KA, Marks JA, Jenoff JS, Cohen MJ, Weinstein MS. Safety of early tracheostomy in trauma patients after anterior cervical fusion. Journal of Trauma and Acute Care Surgery, 2018 Oct. 1; 85 (4): 741-6.

19. Chen KA, Marks JA, Jenoff JS, Cohen MJ, Weinstein MS. Safety of early tracheostomy in trauma patients after anterior cervical fusion. Journal of Trauma and Acute Care Surgery, 2018; 85 (4): 7416.

\section{Additional Information}

Disclosures: Authors report no conflict of interest.

Ethical Review Board Approval: The study was conformed to the ethical review board requirements.

Human Subjects: Consent was obtained by all patients/participants in this study.

Conflicts of Interest:

In compliance with the ICMJE uniform disclosure form, all authors declare the following:

Financial Relationships: All authors have declared that they have no financial relationships at present or within the previous three years with any organizations that might have an interest in the submitted work.

Other Relationships: All authors have declared that there are no other relationships or activities that could appear to have influenced the submitted work.

\section{AUTHORS CONTRIBUTIONS}

\begin{tabular}{|l|l|l|}
\hline Sr.\# & Author's Full Name & Intellectual Contribution to Paper in Terms of: \\
\hline 1. & Aurangzeb Kalhoro & 1. $\quad$ Study design and methodology. \\
\hline 2. & Abdul Samad Panezai & 2. $\quad$ Paper writing, referencing, data calculations and \\
\hline 3. & Sher Hassan & 3. $\quad$ Data collection and calculations. \\
\hline 4. & Farrukh Javeed & 4. $\quad$ Analysis of data and interpretation of results. \\
\hline 5. & Lal Rehman & 5. $\quad$ Literature review and manuscript writing. \\
\hline
\end{tabular}

